\title{
Evaluation of an Afterschool Mentorship Program for Self-Efficacy
}

\author{
Atia D. Mark \\ Walden University \\ Steve Wells \\ Walden University
}

\begin{abstract}
Middle school students in Nova Scotia, Canada, are perceived to have low self-efficacy for achieving learning outcomes. While strong self-efficacy beliefs, developed through effective curricula, have been linked to improved academic performance, there is a need for formal evaluation of such curricula. The purpose of this study was to investigate a 10 -week afterschool mentorship curriculum that has never been evaluated. The aim of the curriculum is to strengthen self-efficacy beliefs via relationship building exercises, public speaking training, and character education. Bandura's theory of self-efficacy, which states that treatment influences can alter the strength of self-efficacy, informed the conceptual framework. Evaluation questions explored apparent changes in the self-efficacy of the students from the perspective of seven adult caregivers and the program's instructor. Interview data were triangulated with quantitative descriptive statistics on the self-efficacy scores of 10 middle school students before and after program participation using the Children's Hope Scale. Comparison of pre- and posttest scores did not show remarkable differences in self-efficacy beliefs of the students. However, analysis of interview data revealed that children's self-efficacy beliefs grew, the largest increase being in those described as reserved at the beginning of the program. This study promotes positive social change through an increased understanding that can inform efforts to increase self-efficacy in middle school students.
\end{abstract}

Keywords: self-efficacy, middle school, afterschool

\section{Introduction}

Strong self-efficacy beliefs prepare students to become self-assured individuals who approach new challenges as exciting tasks to master and not as undesirable undertakings to avoid (Lee, Lee, \& Bong, 2014). Bandura (1997) described self-efficacy as the belief that one can achieve a particular outcome. Self-efficacy can be enhanced through mastery experience (enactive attainment), the modeling of tasks (vicarious experience), ongoing feedback (verbal persuasion), and managing negative emotional stimulus (physiological arousal). Student self-efficacy has long been a topic among educators seeking to improve academic achievement because self-efficacy beliefs are positively related to academic success (Hwang, Choi, Lee, Culver, \& Hutchison, 2016; Ker, 2016; Lucio, Hunt, \& Bornovalova, 2012; Mann, 2013).

The authors acknowledge Dr. Gloria E. Jacobs and Dr. Micheal V. Brunn, who read early versions of this manuscript and provided invaluable feedback. The authors declare that they have no conflict of interest. This study was reviewed and approved by the University Institutional Review Board. 
A private afterschool mentorship (ASM) program in eastern Canada offers an innovative curriculum designed to increase self-efficacy beliefs in middle school students. ASM aims to provide students in third through seventh grades with opportunities for relationship building exercises, public speaking training, and character education, according to the organization's website. By using a community approach, ASM claims to engage students in new experiences to increase self-efficacy beliefs via the development of leadership skills, individual interests, and talents (A. James, personal communication, May 31, 2016). The need for a program like ASM was recognized by its designer, who said, "Students are adults in the making and should be allowed to learn like adults do, through opportunities to experience the world outside the four walls of the classroom" (A. James, personal communication, May 31, 2016). Student testimonials on the ASM website provided anecdotal evidence of its success: "I am more confident in myself and no longer scared to speak in front of a million people. Thank you for everything" (Chloe, Grade 6, 2016). Another student said, "School is just sitting there learning, but [ASM] is . . WOW" (Caitlynn, Grade 4, 2016).

Despite curriculum development designed to improve student self-efficacy (Nova Scotia Education and Early Childhood Development, 2013), a recent survey of over 19,000 educational stakeholders including teachers, adult caregivers, and students in Nova Scotia, Canada, revealed that most middle schoolers are still perceived to have low self-efficacy (Nova Scotia Education and Early Childhood Development, 2015). ASM has never been formally evaluated since its launch in 2014. This 10-week, privately owned program may provide reformers, administrators, and teachers with innovative practices for improving self-efficacy beliefs in middle school students. This study addressed the need for a formal evaluation of ASM and, in a broader sense, the need for additional evaluation of programs that aim to improve self-efficacy beliefs.

The lack of formal evaluations of curricula that aim to improve self-efficacy is evident in the literature. Researchers such as Hushman and Marley (2015); Winnaar, Frempong, and Blignaut (2015); and Fernández-Díaz, Rodríguez-Mantilla, and Jover-Olmeda (2017) have all called on educational policy makers to examine instructional curricula and programs designed to improve selfefficacy beliefs in students. Such recommendations indicated the need to evaluate conventional instructional practice as well as innovative practices that may increase self-efficacy beliefs in middle school students. The purpose of this study was to determine whether ASM successfully improved students' self-efficacy, as well as the potential benefits and drawbacks of program participation.

\section{Method}

Outcome-based evaluations assess how a program meets its main objectives (Worthen, Sanders, \& Fitzpatrick, 1996). We followed the model for program evaluation used by Karahan, CanbazogluBilici, and Unal (2015). These authors used a combined approach of qualitative and quantitative methods to provide a holistic assessment of whether program goals were met. For the current outcome-based program evaluation, we collected and analyzed descriptive quantitative and qualitative data.

\section{Quantitative Data}

Karahan et al. (2015) reported descriptive quantitative pre- and postsurvey data from 21 science, technology, engineering, and mathematics eighth-graders who participated in a 14-week-long research study. The researchers did not conduct inferential statistics on their quantitative data but provided descriptive statistics only. Like Karahan et al. (2015), we did not conduct inferential analysis on the quantitative data; instead, we presented descriptive statistics on students' selfefficacy as measured by the Children's Hope Scale (CHS; Snyder et al., 1997) before and after 10 weeks of program participation. Similarly, Pilkington, Singh, Prescod, and Buettgen (2013) conducted an evaluation of the Mosaic project, a 3-year publicly funded program that sought to 
support diversity in the education of elementary, middle, and high school students considering a profession within the healthcare sector. Data sources included (a) semiformal interviews, (b) written and verbal communication from participants during the project, and (c) enrollment numbers throughout the years. These studies provided evidence that, when inferential analysis is not practical, descriptive quantitative statistics in evaluations having sample sizes that are less than 15 are useful for gaining information regarding participants' perceptions and experiences.

The CHS consists of six questions and uses a 6 -point scale $(1=$ none of the time to $6=$ all of the time $)$. Students responded to each question of the CHS, which included, "My past has prepared me for future success," "I energetically pursue my goals," "There are lots of ways around any problem," and "I can think of many ways to get the things in life that are most important to me" (Snyder et al., 1997, p. 419). Again, the small sample size did not allow us to conduct inferential statistical analysis. We only presented descriptive data. However, the students' pre-post self-efficacy scores provided prima facie support for ASM's main goal of increasing self-efficacy in children. Inductive methods guided the qualitative analysis of semistructured interview data collected from adult caregivers and the lead teacher.

\section{Qualitative Data}

Like Karahan et al. (2015), we conducted semistructured interviews with adult caregivers and the program's designer, who is also the lead teacher. Audiotaped interviews lasted approximately an hour. All questions were open ended and based upon Bandura's conceptual framework. Interview participants had the opportunity to respond honestly and comprehensively. The interview questions, reviewed by a panel of experts in educational research, were clear and aimed to elicit meaningful data about participants' experiences, feelings, and knowledge (Merriam, 2009, p. 114). We interviewed adult caregivers and the teacher mentor twice, once during the third week of the 10 week program and a follow-up interview during the ninth and 10th weeks.

\section{Participants}

We used a convenience sample of all primary adult caregivers from the pool of 10 registered students of the Winter 2017 10-week session. Merriam (2009) noted that convenience sampling is a wellknown method in the qualitative tradition. This form of sampling does not allow for generalization to larger populations but is useful for conveniently accessing participants. All primary adult caregivers of registered students were part of the population best suited for sharing first-hand what they believed to be the value of ASM. However, only seven adult caregivers of registered students who volunteered to participate in the study were invited to take part. The maximum class size was 10, and we expected at least six or seven primary adult caregivers to volunteer for interviews. According to Guest, Bunce, and Johnson (2006), a sample size of six to 12 is ample for data saturation when "the aim is to understand common perceptions and experiences among a relatively homogenous group of individuals" (p. 79).

Other researchers have used similar sample sizes in qualitative research. Monk et al. (2014) used a qualitative approach in assessing EnvironMentors, a program that paired high school students with university student mentors to provide informal environmental science education. To determine whether the program's goals were met, the authors collected qualitative data from nine student surveys, a focus group session with mentors, and written open-ended feedback from students and mentors. 


\section{Results}

\section{Overview of Quantitative Evaluation Findings}

Data analysis revealed the perceived self-efficacy scores of the 10 children in Grades 4 through 8 registered for the Winter 2017 session before and after 10 -weeks of program participation. The total scores for the pretest data were positively skewed. Almost $33 \%$ of the students chose all six items with 5 (most of the time). Additionally, approximately $13 \%$ of the students chose all six items with 6 (all of the time). The average total score of all students $(n=10)$ was 4.1. After program participation, students' average total score increased to 4.62 .

After the conclusion of the 10-week program, almost $30 \%$ of the students chose all six items with 5 (most of the time). In addition, approximately 28\% of students chose all six items with 6 (all of the time) and the average total score of all students $(n=10)$ was 4.62 . Although not supported by inferential analysis, these descriptive data allow for the possibility that ASM does promote selfefficacy in middle school children. Table 1 shows a further breakdown of the pre-post mean scores of the CHS.

Table 1. Descriptive Statistics for Children's Hope Scale (CHS)

\begin{tabular}{lcccccc}
\hline Total Score & $\boldsymbol{n}$ & $\boldsymbol{M}$ & $\boldsymbol{M d n}$ & Mode & Min & Max \\
\hline Pre-CHS & 10 & 4.17 & 4 & 5 & 1 & 6 \\
Post-CHS & 10 & 4.62 & 5 & 5 & 1 & 6 \\
\hline
\end{tabular}

The comparison of mean scores before and after program participation did not show remarkable differences (Table 1). However, there was an upward shift in the distribution of mean and median self-efficacy scores after 10 weeks of program participation (Figure 1). The quantitative data appeared to support the qualitative findings. For example, the interview data described how students who are very reserved when starting the program became much more confident by its end. These reserved students demonstrated the largest increase in self-efficacy beliefs according to the CHS. No conclusion can be drawn from the descriptive statistics about the changes in students' selfefficacy before and after 10 weeks of participation, as inferential statistical analysis was not practical due to the small sample size. Qualitative analysis of the interview data from adult caregivers and the lead teacher, though, indicated there were positive program outcomes leading to increased self-efficacy beliefs.

\section{Overview of Qualitative Evaluation Findings}

The qualitative findings from adult caregivers were consistent with children's self-efficacy scores from the CHS. Many of the adult caregivers felt children's self-confidence to reach for and achieve high goals was mostly high before program participation. However, after program participation, adult caregivers believed children's sense of self-efficacy grew stronger. 


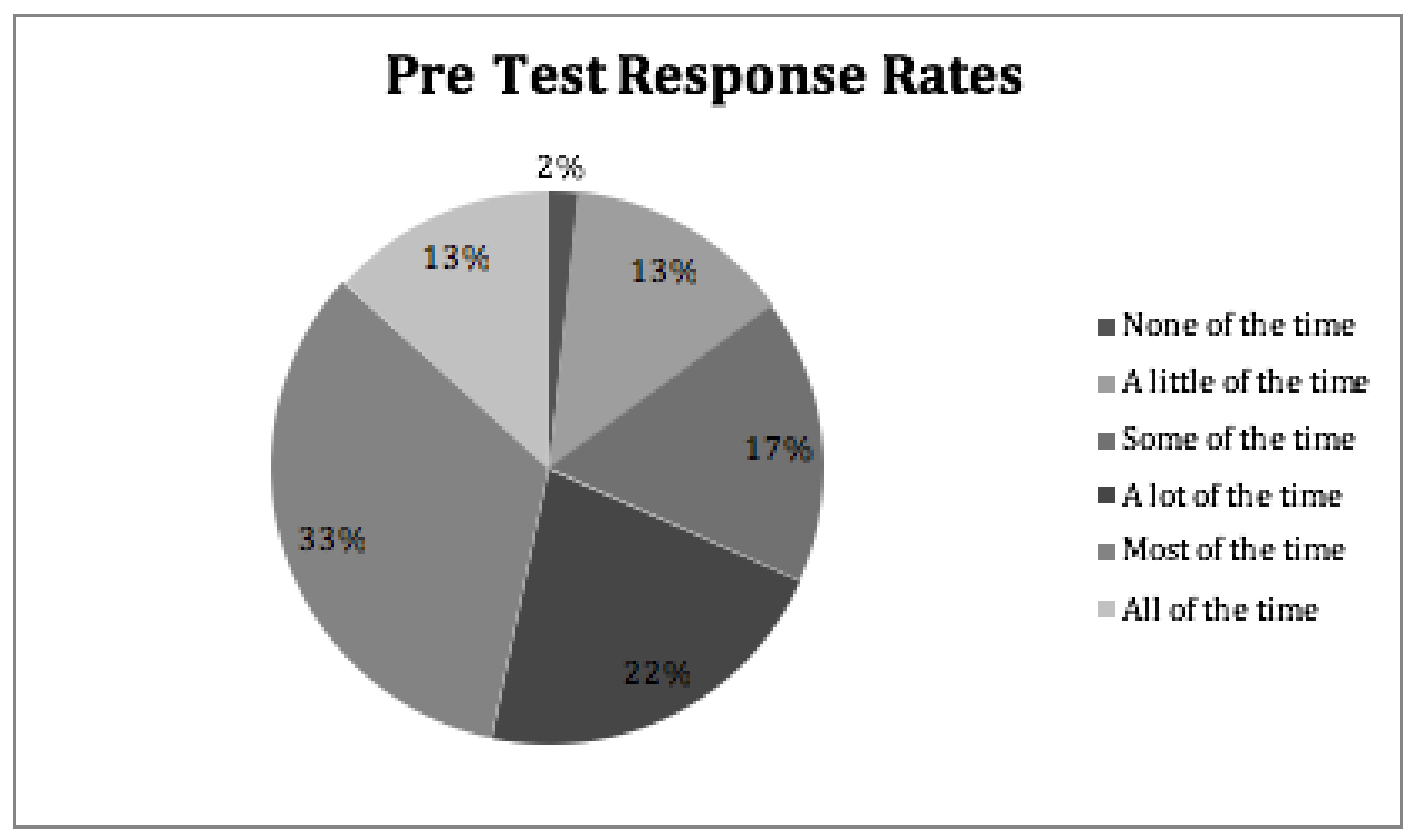

\section{Post Test Response Rates}

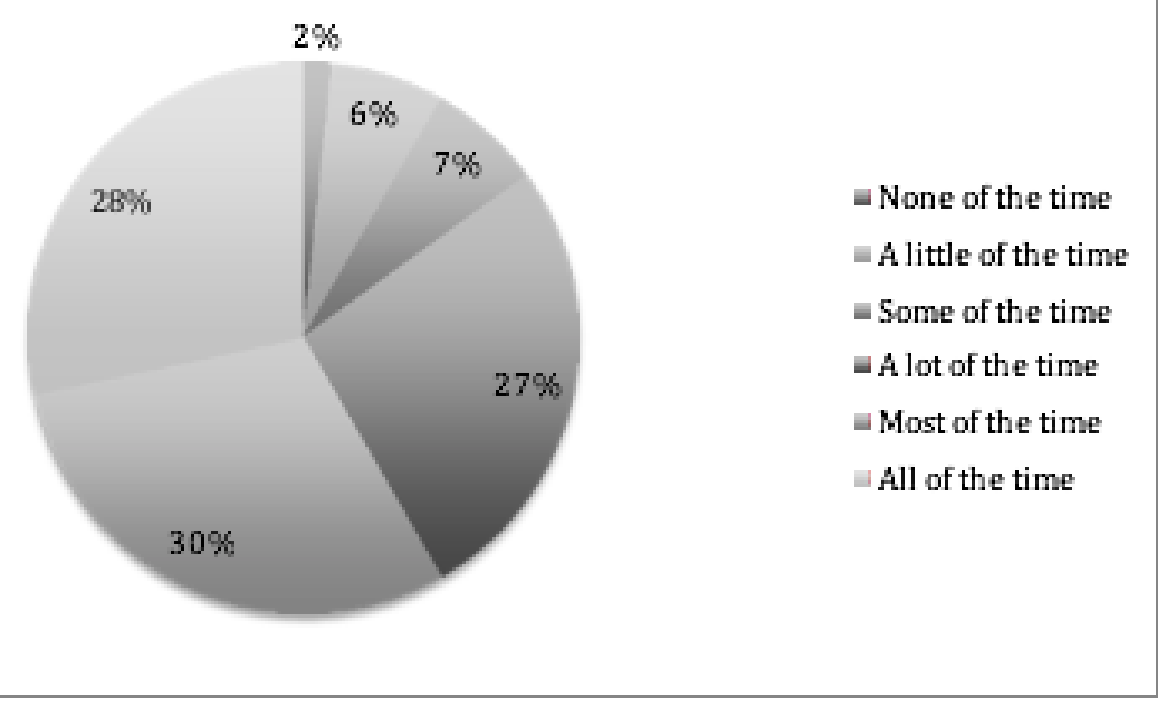

Figure 1. The Children's Hope Scale Pretest and Posttest Scores. This figure illustrates the distribution of pre- and posttest data responses from student participants.

\section{Discussion}

\section{Key Program Strengths}

The lead teacher, Ms. James, and adult caregivers felt that the program provided students with opportunities to increase self-efficacy beliefs. Analysis of qualitative interview data collected suggested that program activities created opportunities for (a) modeling appropriate standards (e.g., table etiquette), (b) mastery transformation that allowed students to succeed (e.g., public speaking training), (c) quality feedback that helped children realize high goals (e.g., one-on-one mentoring), 
and (d) addressing negative emotions such as fear of failure (e.g., positive self-talks). Caregiver 4 said she became "more assertive and outgoing... willing to try new experiences and give it her best." Caregiver 5 said, "She now corrects herself after realizing that she made a negative pronouncement... [she] turns it around to a positive," and Caregiver 3 said, "... she has really opened up... and not as anxious about meeting new people..."

\section{Areas for Program Growth}

Despite the perceived success of the ASM program at improving students' sense of self-efficacy, interview data with the lead teacher and adult caregivers revealed some concerns about the cost attached to this privately offered program. One parent felt that the program was costly, but was willing to make the financial sacrifice to help her daughter "receive the best educational experience possible." The teacher mentor agreed that the program cost limited its availability to children from lower socioeconomic backgrounds.

Ms. James said, "as the sole owner, there is a lot of pressure that comes with sales and running a business in Eastern Canada, in addition to curriculum development and instructional design." According to her, learning to "let go a little of the reigns" and accept "hired help" is becoming more necessary to allow more time for program planning.

The ASM program is privately owned and operated by the lead teacher. She is responsible for all aspects, including marketing and sales promotion, accounting and business taxes, curriculum development and program planning, event organizing, and one-on-one mentoring. The lead teacher noted that a lot of pressure comes with running a private business in Eastern Canada, in addition to curriculum development and instructional design. Although the lead teacher has no formal business education background, a 7-year minicareer in sales and marketing as an assistant public relations director of a not-for-profit organization added personal value. Ms. James said she "wears many hats", which implies that "there is a risk" to program continuity "if [she is] unable to conduct day to day activities."

The problem of program continuity was further investigated during the follow-up interview, and it was discovered that the greatest factor impeding the lead teacher from hiring additional staff is the lack of resources. She went on to explain:

There is no divide between adult and child when it comes to lifestyle choices, who you are as an individual, and what's healthy. Future staff must be sincere, and should not be a different person at home than with the kids. This is what ASM embodies... and it is a heavy responsibility, which cannot be done if it's not one's heart. (A. James, personal communication, January 25, 2018)

According to the lead teacher, with the right support, opportunities for professional development can spark new and creative ideas for further expansion.

\section{Overview of Recommendations}

Several recommendations resulted from the program evaluation. Recommendations included implementing ASM as part of a school-based curriculum to increase program availability to children, incorporating peer-on-peer mentoring into the program, implementing ongoing evaluations of the ASM program, and allowing children to self-enroll in ASM for as long as they require. 


\section{Implement ASM as Part of a School-Based Curriculum to Increase Program Availability to Children}

We concluded that ASM's curriculum and instructional design is beneficial to improving self-efficacy; however, program costs limit its availability to children from lower socioeconomic backgrounds. Policy makers may wish to consider using ASM as a model curriculum in a school-based setting. In one case study, Soni (2015) explored the educational role of a school-based adult learning mentor in emotionally supporting, motivating, managing, and challenging middle school students who experience barriers to learning, such as low self-efficacy. Soni's findings from focus group discussions, observations, and questionnaires suggested that mentoring encourages the educative sharing of best practices that are child centered and provide solution-focused help for students. A school-based self-efficacy curriculum will improve access for children from lower socioeconomic backgrounds.

\section{Sustain the Program Through Peer-on-Peer Mentoring}

The lead teacher-mentor, who is also the designer of the program, operated the entire ASM program solely. Adult support is crucial when attempting to strengthen self-efficacy in children. Fruiht and Wray-Lake (2013) noted that adult teacher-mentors with higher education training have experience in navigating the educational system and can provide academic resources to mentees. Additionally, peer-on-peer mentoring may also be used to a greater degree in ASM. Although a teacher-mentor offers student learners comprehensive guidance for improving self-efficacy (Fitzpatrick, 2013), peeron-peer feedback may also have a positive influence on the self-efficacy of other students. Strapp et al. (2014) suggested that giving positive feedback is an important aspect of peer-on-peer mentoring because it highlights how children might achieve high self-efficacy. Uçar and Sungur (2017) added that children with a strong sense of self-efficacy tend to motivate themselves to achieve goals and motivate higher self-efficacy among their peers. So, we recommend expansion of peer-mentoring to reinforce the adult's role in ASM.

\section{Implement a Continuous Evaluation System That Includes Program Stakeholders}

Innovative programs such as ASM should be evaluated in a continuous manner to generate improvement and gauge their success. We suggest using both a quantitative and qualitative approach to data analysis. With larger sample sizes, statistical analysis of the CHS will be more informative. This may be possible if the data is collected in an efficient and ongoing manner. Qualitative feedback on the program is also important to the ongoing evaluation. Monk et al. (2014) used a mixed approach to assessing EnvironMentors, a program that paired high school students with university student mentors to provide informal environmental science education. To determine whether the program's goals were met, the authors collected data from student surveys, a focus group session with mentors during the first year, and written open-ended feedback from students and mentors during the second year. Monk et al. demonstrated data collection methods that may be useful for evaluation of ASM.

Continual evaluation of ASM will increase the workload for the program. Administrators of the program may consider hiring an external evaluator. The funding costs, time, and resources necessary to execute additional responsibilities must be borne by the program.

\section{Allow Children to Self-Enroll in ASM for as Long as They Require}

Allowing students to self-enroll for ASM gives them voice and choice in their own learning. The current system is limited to 10 weeks. Students should be able to choose to register for ASM based on their perceived need for self-efficacy development. According to King and Howard (2016), students tend to be positively motivated when teachers provide them with the ability to choose their learning goals. Moreover, Hu and Zhang (2017) confirmed the importance of allowing students choice in activities when building self-efficacy. Furthermore, Aho et al. (2015) found that self-directed learning 
helps children achieve personal goals. Informal learning environments, such as afterschool programs, can encourage self-directed learning. We recommend that the opportunity be offered on a longer term basis.

\section{Conclusion}

The findings from this study may empower future curriculum writers and school leaders to provide unique learning experiences that increase self-efficacy in middle schoolers, make informed data driven decisions with regard to policies and procedures affecting students with low self-efficacy, use data to maintain self-efficacy curricula, and initiate a process for the formal evaluation of programs from the perspective of primary stakeholders.

\section{References}

Aho, J. M., Ruparel, R. K., Graham, E., Zendejas-Mummert, B., Heller, S. F., Farley, D. R., \& Bingener, J. (2015). Mentor-guided self-directed learning affects resident practice. Journal of Surgical Education, 72, 674-679. doi:10.1016/j.jsurg.2015.01.008

Bandura, A. (1997). Self-efficacy: The exercise of control (Vol. 4). New York, NY: Freeman.

Fernández-Díaz, M. J., Rodríguez-Mantilla, J. M., \& Jover-Olmeda, G. (2017). Evaluation of the impact of intervention programmes on education organisations: Application to a quality management system. Evaluation and Program Planning, 63, 116-122. doi:10.1016/j.evalprogplan.2017.04.005

Fitzpatrick, J. (2013). The application of Kram's mentorship functions to a service learning assignment. Journal of College and Character, 14, 185-192. doi:10.1515/jcc-2013- 0024

Fruiht, V. M., \& Wray-Lake, L. (2013). The role of mentor type and timing in predicting educational attainment. Journal of Youth and Adolescence, 42, 1459-1472. doi:10.1007/s10964-012-9817-0

Guest, G., Bunce, A., \& Johnson, L. (2006). How many interviews are enough? An experiment with data saturation and variability, Field Methods, 18, 59-82.

Hu, P., \& Zhang, J. (2017). A pathway to learner autonomy: A self-determination theory perspective. Asia Pacific Education Review, 18, 147-157. doi:10.1007/s12564-016-9468-z

Hushman, C. J., \& Marley, S. C. (2015). Guided instruction improves elementary student learning and self-efficacy in science. Journal of Educational Research, 108, 371-381. doi:10.1080/00220671.2014.899958

Hwang, M., Choi, H., Lee, A., Culver, J., \& Hutchison, B. (2016). The relationship between selfefficacy and academic achievement: A 5-year panel analysis. Asia-Pacific Education Researcher, 25, 89-98. doi:10.1007/s40299-015-0236-3

Karahan, E., Canbazoglu-Bilici, S., \& Unal, A. (2015). Integration of media design processes in science, technology, engineering, and mathematics (STEM) education. Eurasian Journal of Educational Research, 60, 221-240. doi:10.14689/ejer.2015.60.1

Ker, H. W. (2016). The impacts of student-, teacher- and school-level factors on mathematics achievement: An exploratory comparative investigation of Singaporean students and the USA students. Educational Psychology, 36, 254-276. doi:10.1080/01443410.2015.1026801

King, P., \& Howard, J. (2016). Free choice or adaptable choice: Self-determination theory and play. American Journal of Play, 9, 56-70. Retrieved from https://cronfa.swan.ac.uk/Record/cronfa30590\#details 
Lee, W., Lee, M.-J., \& Bong, M. (2014). Testing interest and self-efficacy as predictors of academic self-regulation and achievement. Contemporary Educational Psychology, 39, 86-99. doi:10.1016/j.cedpsych.2014.02.002

Lucio, R., Hunt, E., \& Bornovalova, M. (2012). Identifying the necessary and sufficient number of risk factors for predicting academic failure. Developmental Psychology, 48, 422-428. doi:10.1037/a0025939

Mann, M. J. (2013). Helping middle school girls at risk for school failure recover their confidence and achieve school success: An experimental study. Research in Middle Level Education, 36, $1-14$.

Merriam, S. B. (2009). Qualitative research: A guide to design and implementation (2nd ed.). San Francisco, CA: Jossey-Bass.

Monk, M. H., Baustian, M. M., Saari, C. R., Welsh, S., D’Elia, C. F., Powers, J. E., \& Francis, P. (2014). EnvironMentors: Mentoring at-risk high school students through university partnerships. International Journal of Environmental \& Science Education, 9, 385. Retrieved from https://eric.ed.gov/?id=EJ1048061

Nova Scotia Education and Early Childhood Development. (2013). Community-based learning. Retrieved from https://www.ednet.ns.ca/community-based-learning-0

Nova Scotia Education and Early Childhood Development. (2015). Homework policy. Retrieved from https://www.ednet.ns.ca/homeworkpolicy.pdf

Pilkington, F. B., Singh, M. D., Prescod, C., \& Buettgen, A. (2013). Inclusive mosaic: Promoting diversity in nursing through youth mentorship. International Journal of Nursing Education Scholarship, 10, 1-10. doi:10.1515/ijnes-2012-0012

Snyder, C. R., Hoza, B., Pelham, W. E., Rapoff, M., Ware, L., Danovsky, M., . . Stahl, K. J. (1997). The development and validation of the children's hope scale. Journal of Pediatric Psychology, 22, 399-421. doi:10.1093/jpepsy/22.3.399

Soni, A. (2015). A case study on the use of group supervision with learning mentors. Educational \& Child Psychology, 32, 65-77.

Strapp, C. M., Gilles, A. W., Spalding, A. E., Hughes, C. T., Baldwin, A. M., Guy, K. L., \& Lamb, A. D. (2014). Changes in mentor efficacy and perceptions following participation in a youth mentoring program. Mentoring \& Tutoring: Partnership in Learning, 22, 190-209.

Uçar, F. M., \& Sungur, S. (2017). The role of perceived classroom goal structures, self-efficacy, and engagement in student science achievement. Research in Science \& Technological Education, 35, 149-168. doi:10.1080/02635143.2017.1278684

Winnaar, L. D., Frempong, G., \& Blignaut, R. (2015). Understanding school effects in SouthAfrica using multilevel analysis: Findings from TIMSS 2011. Electronic Journal of Research in Educational Psychology, 13, 151-170. doi:10.14204/ejrep.35.13116

Worthen, B. R., Sanders, J. R., \& Fitzpatrick, J. L. (1996). Program evaluation: Alternative approaches and practical guidelines (2nd ed.). New York, NY: Pearson. 
The Journal of Educational Research and Practice provides a forum for studies and dialogue that allows readers to better develop social change in the field of education and learning. Journal content may focus on educational issues of all ages and in all settings. It also presents peer-reviewed commentaries, book reviews, interviews of prominent individuals, and additional content. The objectives: We publish research and related content that examines current relevant educational issues and processes aimed at presenting readers with knowledge and showing how that knowledge can be used to impact social change in educational or learning environments. Additional content provides an opportunity for scholarly and professional dialogue regarding that content's usefulness in expanding the body of scholarly knowledge and increasing readers' effectiveness as educators. The journal also focuses on facilitating the activities of both researcher-practitioners and practitioner-researchers, providing optimal opportunities for interdisciplinary and collaborative thought through blogging and other communications.

Walden University Publishing: http://www.publishing.waldenu.edu 